\title{
SHP-2 acts via ROCK to regulate the cardiac actin cytoskeleton
}

\author{
Yvette Langdon $1,3, *$, Panna Tandon ${ }^{1,3, *}$, Erika Paden ${ }^{1,2}$, Jennifer Duddy ${ }^{3}$, Joan M. Taylor ${ }^{1,4}$ and \\ Frank L. Conlon ${ }^{1,2,3, \pm}$
}

\begin{abstract}
SUMMARY
Noonan syndrome is one of the most common causes of human congenital heart disease and is frequently associated with missense mutations in the protein phosphatase SHP-2. Interestingly, patients with acute myelogenous leukemia (AML), acute lymphoblastic leukemia (ALL), juvenile myelomonocytic leukemia (JMML) and LEOPARD syndrome frequently carry a second, somatically introduced subset of missense mutations in SHP-2. To determine the cellular and molecular mechanisms by which SHP2 regulates heart development and, thus, understand how Noonan-associated mutations affect cardiogenesis, we introduced SHP2 encoding the most prevalent Noonan syndrome and JMML mutations into Xenopus embryos. Resulting embryos show a direct relationship between a Noonan SHP-2 mutation and its ability to cause cardiac defects in Xenopus; embryos expressing Noonan SHP-2 mutations exhibit morphologically abnormal hearts, whereas those expressing an SHP-2 JMML-associated mutation do not. Our studies indicate that the cardiac defects associated with the introduction of the Noonan-associated SHP-2 mutations are coupled with a delay or arrest of the cardiac cell cycle in M-phase and a failure of cardiomyocyte progenitors to incorporate into the developing heart. We show that these defects are a result of an underlying malformation in the formation and polarity of cardiac actin fibers and F-actin deposition. We show that these defects can be rescued in culture and in embryos through the inhibition of the Rho-associated, coiled-coil-containing protein kinase 1 (ROCK), thus demonstrating a direct relationship between SHP-2 ${ }^{\mathrm{N} 308 \mathrm{D}}$ and ROCK activation in the developing heart.
\end{abstract}

KEY WORDS: Heart development, Cardiomyocyte, Xenopus

\section{INTRODUCTION}

SHP-2, also known as SH-PTP2, Ptpn11, PTP1D, PTP2C, or corkscrew (Csw), is a widely expressed protein known to function genetically and biochemically downstream of a number of growth factors that signal through single-pass tyrosine kinase receptors, including the epidermal growth factors (EGFs), the fibroblast growth factors (FGFs) and platelet derived growth factor (PDGF) (Feng, 1999; Pawson, 1994; Qu, 2000; Van Vactor et al., 1998; Zhang et al., 2000). A role for SHP-2 in vertebrate heart development was demonstrated through the observation that missense mutations are often associated with Noonan syndrome, one of the most common human congenital heart diseases that leads to a number of cardiac developmental abnormalities, including atrial septal defects, ventricular septal defects, pulmonary stenosis and hypertrophic cardiomyopathy (Kosaki et al., 2002; Maheshwari et al., 2002; Noonan, 1968; Noonan, 1994; Tartaglia et al., 2002; Tartaglia et al., 2001). Interestingly, patients with acute myelogenous leukemia (AML), acute lymphoblastic leukemia (ALL), juvenile myelomonocytic leukemia (JMML) and LEOPARD syndrome frequently carry a second, somatically introduced subset of missense mutations in SHP-2 (Bentires-Alj et al., 2004; Digilio et al., 2002; Kratz et al., 2005; Legius et al., 2002; Loh et al., 2004; Musante et al., 2003; Tartaglia et al., 2003).

\footnotetext{
${ }^{1}$ University of North Carolina McAllister Heart Institute, UNC-Chapel Hill, Chapel Hill, NC 27599-3280, USA. 'Department of Biology, UNC-Chapel Hill, Chapel Hill, NC 27599-3280, USA. ${ }^{3}$ Department of Genetics, UNC-Chapel Hill, Chapel Hill, NC

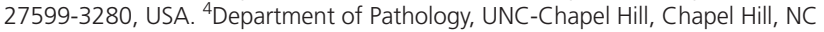
27599, USA.

*These authors contributed equally to this work

${ }^{\ddagger}$ Author for correspondence (frank_conlon@med.unc.edu)
}

Accepted 20 December 2011
The sequence, expression pattern and function of SHP-2 are highly conserved throughout evolution. For example, Xenopus and human orthologs share $94 \%$ sequence identity and, as in fly and mouse, Xenopus SHP-2 is believed to be ubiquitously expressed (Langdon et al., 2007; Tang et al., 1995). Moreover, a number of animal models have suggested a crucial role for SHP-2 in vertebrate development. For instance, mice mutant for an internal deletion of the amino-terminal (N-SH2) domain of SHP-2 die during late gastrulation and display several mesodermal abnormalities, including heart and vascular defects (Saxton et al., 1997; Saxton and Pawson, 1999; Yang et al., 2006a). Similarly, Xenopus expressing a dominant-negative form of SHP-2 also arrest at gastrulation (Tang et al., 1995). Furthermore, SHP-2 is required for full and sustained activation of the MAPK pathway in response to FGF in primary fibroblast cells, indicating that SHP-2 functions downstream of the FGF/MAPK pathway in vivo (Saxton et al., 1997; Saxton and Pawson, 1999).

Despite the crucial role for SHP-2 in cardiac development and disease, the endogenous role for SHP-2 in heart development and its function in Noonan syndrome, AML, ALL, JMML and LEOPARD syndrome remains poorly defined. To address these issues further and to identify the cellular and biochemical pathways that function downstream of SHP-2 in heart development, we generated the most prevalent human Noonan and JMML mutations in SHP-2 and introduced these into Xenopus. Our results revealed a direct relationship between Noonan mutations and the ability of SHP-2 to cause heart defects in Xenopus. Our studies indicate that the cardiac defects associated with the introduction of the Noonanassociated SHP-2 mutations are coupled with a delay or arrest of the cardiac cell cycle in M-phase and a failure of cardiomyocyte progenitors to be incorporated into the developing heart. We go on to show that these defects are a result of an underlying 
malformation in the arrangement and polarity of cardiac actin fibers and F-actin deposition. Furthermore, we show that these defects can be rescued in culture and in embryos through the inhibition of the Rho-associated, coiled-coil containing protein kinase 1 (ROCK), thus demonstrating a direct relationship between SHP-2 ${ }^{\mathrm{N} 308 \mathrm{D}}$ and ROCK activation in the developing heart. Taken together, these studies provide insights into the cellular and molecular mechanisms by which SHP-2 functions in cardiac development and disease.

\section{MATERIALS AND METHODS}

\section{DNA constructs and embryo injections}

SHP-2 ${ }^{\text {FL }}$ and SHP-2 ${ }^{\text {E76A }}$ were kindly provided by Nikola Pavletich (Georgescu et al., 2000). SHP-2 ${ }^{\mathrm{N} 308 \mathrm{D}}$ and SHP-2 ${ }^{\mathrm{N} 308 \mathrm{D}-\mathrm{PTP}}$ were generated by site-directed mutagenesis (Stratagene). All constructs were subcloned into an HA-modified pcDNA3.1 vector. SHP-2 ${ }^{\mathrm{D} 61 \mathrm{G}}$ and SHP-2 $2^{\mathrm{Q} 79 \mathrm{R}}$ were generated by site-directed mutagenesis of HA-SHP-2 ${ }^{\mathrm{FL}}$ (Genscript, NJ, USA). See supplementary material Table $\mathrm{S} 1$ for primer sequences and cloning details. Xenopus embryos were staged according to Nieuwkoop and Faber (Nieuwkoop and Faber, 1975) and injected with RNA at the stated concentrations at the one-cell stage unless otherwise noted using established protocols (Smith and Slack, 1983; Wilson and HemmatiBrivanlou, 1995).

\section{Mitotic index and apoptosis}

To calculate the mitotic index and index for programmed cell death, embryos at the reported stages were serial-sectioned $(14 \mu \mathrm{m})$ through the cardiac regions and triple immunostained with anti-tropomyosin (Tmy) to mark cardiomyocytes, DAPI to mark cell nuclei, and either anti-phospho histone $\mathrm{H} 3$ (pH3) (1:200; Upstate) to mark cells in M phase or anticaspase-3 (1:50; Pharmingen) to mark cells undergoing apoptosis. Indices were determined by counting all triple-positive cells within the heart from all sections relative to the total number of Tmy-DAPI double-positive cells. All studies were carried out with at least three embryos and repeated at least twice (i.e. two independent rounds of injections) except for stage 33, which was conducted four independent times. Results are reported as the ratio of triple to double positive cells \pm two standard deviations by Student's $t$-test as previously described (Goetz et al., 2006; Langdon et al., 2007)

\section{Western blot analysis}

All experiments on embryos were conducted as reported previously (Goetz et al., 2006; Langdon et al., 2007). Densitometry was used to standardize loading levels in western blot analysis. Embryonic tissue was lysed in modified RIPA buffer (10 mM Tris $\mathrm{pH} 7.5,50 \mathrm{mM} \mathrm{NaCl}, 1 \mathrm{mM}$ EDTA, $1 \mathrm{mM}$ EGTA, $20 \mathrm{mM} \mathrm{Na} \mathrm{P}_{2} \mathrm{O}_{7}, 1 \%$ Triton X-100) containing a cocktail of inhibitors including $1 \mathrm{mM} \mathrm{Na} \mathrm{VO}_{4}, 40 \mathrm{mM} \mathrm{NaF}, 10 \mathrm{mM}$ sodium pyrophosphate, $100 \mu \mathrm{m}$ leupeptin, $1 \mathrm{mM} \mathrm{4-(2-aminoethyl)}$ benzenesulfonyl fluoride hydrochloride, $0.02 \mathrm{mg} / \mathrm{ml}$ soybean trypsin inhibitor and $0.05 \mathrm{U} / \mathrm{ml}$ aprotinin. Samples were clarified by centrifugation twice at $14,000 \mathrm{~g}$ at $4{ }^{\circ} \mathrm{C}$ and $50 \mu \mathrm{g}$ of total protein was loaded onto a $10 \%$ SDS-acrylamide gel. Separated proteins were transferred onto nitrocellulose, blocked in 5\% dry milk in Tris-buffered saline $+0.1 \%$ Tween for 1 hour and incubated overnight at $4{ }^{\circ} \mathrm{C}$ with primary antibody (1:1000) in blocking solution. Blots were incubated with the appropriate horseradish peroxidase-conjugated secondary antibodies (1:2000) and proteins were visualized by chemiluminescence. Data are representative of three separate experiments with similar results. Antibodies used were: anti-HA, anti-EF-2, (Zymed, 1:1000) and antiSHP-2 (BD Transduction Laboratories, 1:2500).

\section{TBX5 antibody, immunohistochemistry, in situ hybridization and} 3D modeling

$\mathrm{HIS}_{6}$-Maltose binding protein (MBP) was fused in-frame to the C-terminal 287 amino acids of Xenopus TBX5 and the resulting construct was expressed in BL21 cells. Protein was purified on nickel resin, concentrated on a Millipore column with $30,000 \mathrm{kDa}$ molecular weight cut-off and resolved by gel electrophoresis. A band corresponding to TBX5 was excised and injected into rabbits to generate polyclonal antibodies (Covance). Antiserum was used to detect TBX5 in immunohistochemistry (1:500). In situ hybridization was performed as previously reported (Langdon et al., 2007). Global software, a 3D reconstruction program, was adapted from a program by Stephen Aylward, Remi Charrier and Cedric Caron at the University of North Carolina. Antibodies used in immunohistochemistry were: mouse anti-tropomyosin (1:50), mouse antitroponin (1:20), mouse anti-fibrillin (1:50) (all from Developmental Studies Hybridoma Bank), mouse anti-MHC (1:500; Abcam), rabbit antifibronectin (1:50; Sigma), rabbit anti-phospho histone H3 (1:50; Upstate) and rabbit anti-cleaved caspase-3 (1:50; Cell Signaling).

\section{Histology and transmission electron microscopy}

Embryos were fixed in 2\% paraformaldehyde $2.5 \%$ glutaraldehyde overnight, post-fixed in ferrocyanide-reduced osmium and embedded in Spurr's epoxy resin. Transverse thick $(1 \mu \mathrm{m})$ sections were mounted on slides and stained with $1 \%$ Toluidine Blue in $1 \%$ sodium borate. Sections were imaged using a Leica DMIRB inverted scope. Transmission electron microscopy (TEM) was conducted according to Brown et al. (Brown et al., 2007).

Cell culture, SHP-2 plasmid transfection and ROCK inhibition assay Mesenchymal cells (10T1/2) were obtained from ATCC and cultured at subconfluent density Dulbecco's modified eagle media with 10\% FBS and penicillin/streptomycin. Cells were transfected with the indicated cDNA constructs for 24 hours according to manufacturer's specifications using LT-1 (Mirus). Cells were then trypsinized and plated on glass chamber slides $\left(5000\right.$ cells $\left./ \mathrm{cm}^{2}\right)$ pre-coated with fibronectin $(\mathrm{FN} ; 10 \mu \mathrm{g} / \mathrm{ml})$ in serum-free medium. At the specified time points, slides were washed three times with PBS (calcium- and magnesium-free), fixed in $4 \%$ paraformaldehyde (PFA) in PBS for 20 minutes, washed three times in PBS and permeabilized for 3 minutes with $4 \%$ Triton X-100 in PBS followed by three washes with PBS and then blocked with $20 \%$ goat serum, $3 \%$ bovine serum albumin in PBS for 30 minutes. Cells were incubated with primary antibodies rabbit anti-pY31 paxillin (Invitrogen), mouse anti-HA (Santa Cruz) (both 1:1000) or with Texas Red phalloidin (1:500) to visualize filamentous actin for 1 hour at room temperature followed by 1 hour incubation with appropriate Alexa 488- or cy5congugated secondary antibody. For the ROCK activity rescue assay, transfected cells (after a 20 minute recovery period to allow for spreading) were incubated with either vehicle or the pharmacological ROCK inhibitor Y27632 (Sigma; $10 \mu \mathrm{M}$ ) for an additional 20-160 minutes. Cells were processed for immunocytochemistry as described above.

\section{ROCK pharmacological inhibitor rescue assay}

Embryos were injected with SHP-2 ${ }^{\mathrm{N} 308 \mathrm{D}}$ RNA at the one-cell stage and collected at stage 28. Uninjected and RNA-injected sibling embryos were placed in a 6-well dish in $0.1 \times$ MBS supplemented with $10 \mu \mathrm{M}$ Y 27632 and incubated at room temperature until stage 40. Embryos were fixed in $4 \%$ PFA with $0.1 \%$ Tween and processed for immunohistochemistry. Statistical significance of rescue was calculated using Fisher's exact test based on three independent experiments.

\section{RESULTS}

The Noonan syndrome-associated mutation SHP-2 ${ }^{\text {N308D }}$ leads to abnormal heart development in Xenopus

Noonan syndrome missense mutations in SHP-2 occur in approximately half of affected individuals. Interestingly, humans with juvenile myelomonocytic leukemia (JMML) carry a second somatically introduced subset of missense mutations (Kosaki et al., 2002; Maheshwari et al., 2002; Tartaglia et al., 2002; Tartaglia et al., 2001). To test the relationship between specific SHP-2 missense mutations and normal heart development further, we engineered the most prevalent Noonan and JMML mutations, encoding for SHP$2^{\mathrm{N} 308 \mathrm{D}}$ and SHP-2 ${ }^{\mathrm{E} 76 \mathrm{~A}}$, respectively (Fig. 1A), and introduced them into Xenopus (Kosaki et al., 2002; Maheshwari et al., 2002; 

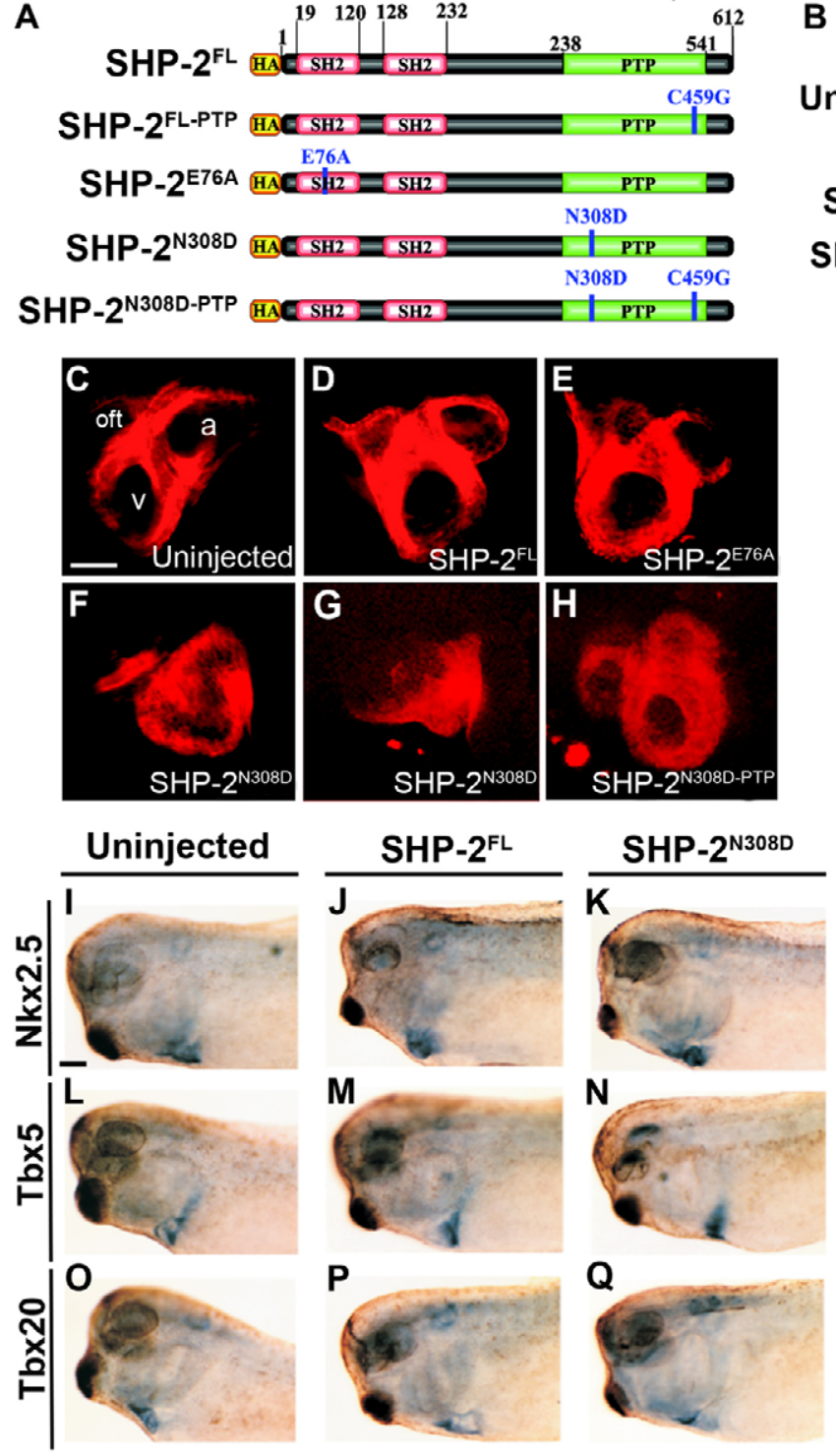

Tartaglia et al., 2002; Tartaglia et al., 2001). Tropomyosin (Tmy) staining of resultant embryos at late tadpole stages (stage 36) showed a direct relationship between a Noonan mutation and the ability to cause heart defects in Xenopus; embryos derived from injections of either full-length wild-type SHP-2 (SHP-2 $\left.{ }^{\mathrm{FL}}\right)$ or the JMML SHP-2 mutation SHP-2 ${ }^{\text {E76A }}$ were indistinguishable from uninjected controls, whereas embryos derived from the introduction of Noonan mutation SHP-2 ${ }^{\mathrm{N} 308 \mathrm{D}}$ had smaller hearts that failed to complete looping or undergo chamber formation (Fig. 1C-H). We observed further that the defects associated with SHP-2 $2^{\mathrm{N} 308 \mathrm{D}}$ at these stages were confined to cardiac tissue and we could not detect any other developmental abnormalities even at high concentrations (4 ng; data not shown). In further support of Noonan-associated mutations having an effect on Xenopus heart development, the introduction of RNA encoding SHP-2 ${ }^{\mathrm{D} 61 \mathrm{G}}$ and SHP-2 ${ }^{\mathrm{Q} 79 \mathrm{R}}$, two additional mutations associated with Noonan syndrome localizing to the same region of SHP-2 as SHP-2 ${ }^{\mathrm{E} 76 \mathrm{~A}}$, were able to induce similar cardiac defects to SHP-2 ${ }^{\mathrm{N} 308 \mathrm{D}}$ (supplementary material Fig. $\mathrm{S} 1$ ). Collectively, these results demonstrate a direct relationship between Noonan-associated mutations in SHP-2 and cardiac defects in Xenopus.

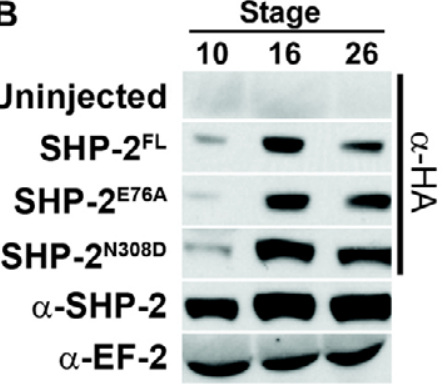

Fig. 1. Noonan-associated mutation of SHP-2 leads to heart defects in Xenopus. (A) Schematic of SHP-2 constructs. Note that constructs used in Xenopus in vivo experiments were not epitope tagged with $\mathrm{HA}$. (B) Western blot analysis of embryo lysates from embryos injected with the respective HA epitope-tagged SHP-2 constructs at stages 10 (gastrula), 16 (early neurula) and 26 (late neurula) probed with an anti-HA antibody, an anti-SHP-2 antibody that recognizes both endogenous and introduced versions of SHP-2, and an anti-EF-2 antibody as a loading control. (C-

H) Whole-mount antibody staining of cleared stage 36 embryos with antitropomyosin antibody (Tmy). Anterior is to the left, posterior to the right. Scale bar: $100 \mu \mathrm{m}$. (I-Q) Whole-mount in situ hybridization of cleared stage 33 from uninjected $(\mathrm{I}, \mathrm{L}, \mathrm{O}), \mathrm{SHP}-2^{\mathrm{FL}}$ (2 ng; J,M,P) and SHP-2 ${ }^{\mathrm{N} 308 \mathrm{D}}$ (2 ng; $\mathrm{K}, \mathrm{N}, \mathrm{Q}$ ) embryos probed for Nkx2.5 (IK), Tbx5 (L-N) or Tbx20 (O-Q). Scale bar: $1 \mathrm{~mm}$. a, atrium; oft, outflow tract; $v$, ventricle.
As we observed no differences in protein levels between controls and Noonan SHP-2 ${ }^{\text {N308D }}$ or JMML constructs (Fig. 1B), the cardiac defects associated with SHP-2 ${ }^{\mathrm{N} 308 \mathrm{D}}$, and potentially SHP-2 ${ }^{\mathrm{D} 61 \mathrm{G}}$ and SHP-2 ${ }^{\text {Q79R }}$, were not associated with alterations in either RNA or protein stability. Furthermore, although expression of injected SHP-2 ${ }^{\text {N308D }}$ RNA was ubiquitous (data not shown) we could detect no erroneous or ectopic expression of cardiac specification makers Nkx2.5, Tbx 5 or Tbx20 by whole-mount in situ hybridization at or before stage 33 (Fig. 1I-Q). Thus, these results imply that the cardiac defects associated with SHP-2 ${ }^{\mathrm{N} 308 \mathrm{D}}$ and associated Noonansyndrome mutations are restricted to cardiac tissue. As a direct test of this hypothesis, we introduced a version of SHP-2 ${ }^{\mathrm{N} 308 \mathrm{D}}$ carrying

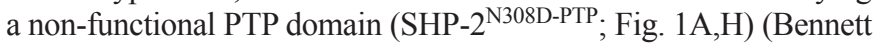
et al., 1996) and showed that SHP-2 $2^{\text {N308D-PTP }}$ gave rise to embryos with hearts that were indistinguishable from either SHP- $2^{\mathrm{FL}}$ or uninjected controls (Fig. 1A,C,D,F-H). As it has been demonstrated that the Noonan-associated mutation SHP-2 ${ }^{\mathrm{N} 308 \mathrm{D}}$ has a higher level of phosphatase activity then that of full-length SHP-2 (Tartaglia et al., 2003) (F.L.C., unpublished), our results imply that alterations in SHP-2 phosphatase activity in the Noonan mutation SHP-2 ${ }^{\text {N308D }}$ might lead to cardiac-specific defects in Xenopus. 

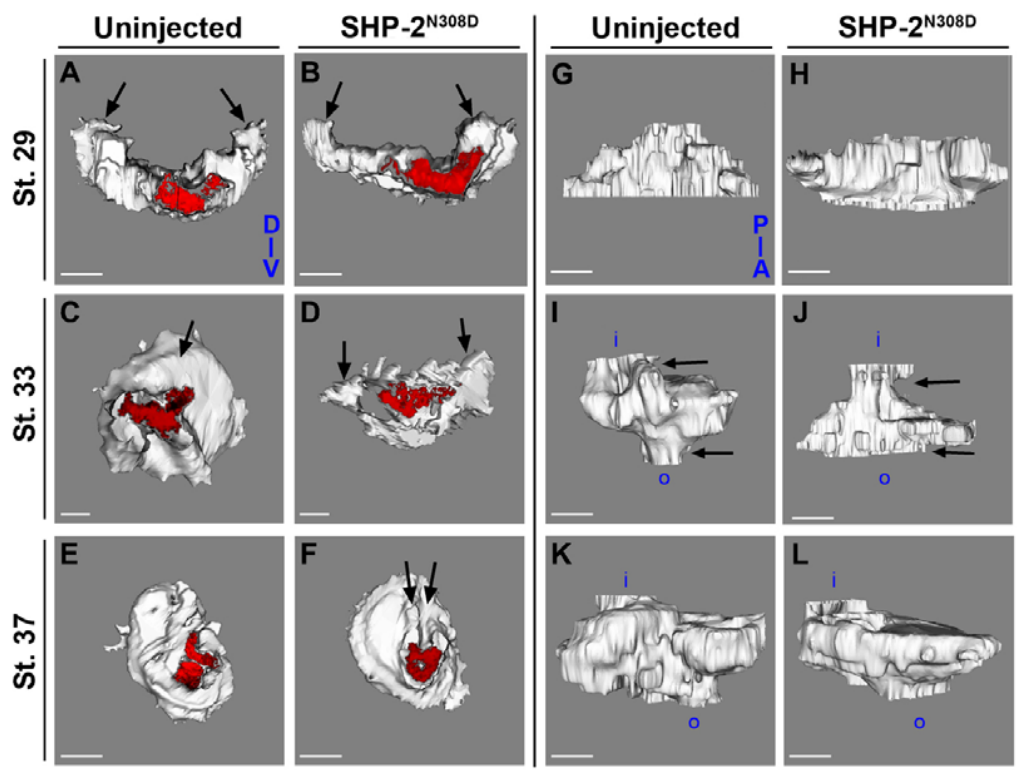

Fig. 2. 3D modeling of uninjected and SHP-2 ${ }^{\mathrm{N} 308 \mathrm{D}}$ cardiac tissue. (A-L) 3D modeling of Tmy expression in stage $29(A, B, G, H)$, stage $33(C, D, I, J)$ and stage $37(E, F, K, L)$ Xenopus embryos. In A-F, hearts are viewed from anterior to posterior and red denotes the most anterior section of the heart. In $\mathrm{G}-\mathrm{L}$, hearts are viewed from the dorsal side. Arrows in A-F denote ends of cardiac trough. Note that in $\mathrm{C}$ the trough has closed across the dorsal midline in uninjected control but remains open in SHP-2 ${ }^{\mathrm{N} 308 \mathrm{D}}$ heart (2 ng; D). Edges of the trough come together by stage 37 $(\mathrm{F})$ in the SHP-2 ${ }^{\mathrm{N} 308 \mathrm{D}}$ heart but have not closed across the ventral midline (arrows). Also, at stage 33 (J), the SHP$2^{\mathrm{N} 308 \mathrm{D}}$ heart is much wider in anterior portions but is much thinner in posterior portions (arrows) versus corresponding control (I). Note the relative orientation of the outflow tract (o) to the inflow tract (i) in I versus J, indicative of a delay in looping. a, anterior; d, dorsal; p, posterior; v, ventral. Scale bars: $50 \mu \mathrm{m}$

\section{The Noonan-associated mutation SHP-2 ${ }^{\mathrm{N308D}}$ leads to defects in cardiac morphology}

To gain a further understanding of the cellular defects and to determine the precise onset of the SHP- $2^{\mathrm{N} 308 \mathrm{D}}$-induced cardiac defects, we conducted 3D imaging on embryos derived from the introduction of SHP-2 ${ }^{\mathrm{N} 308 \mathrm{D}}$ compared with uninjected controls. Consistent with our in situ hybridization analysis, we did not detect any global developmental abnormalities in SHP-2 ${ }^{\mathrm{N} 308 \mathrm{D}}$-derived embryos at stage 29 (Fig. 2A,B,G,H). However, by stage 33, when control embryos have formed a bilaminar heart tube after dorsal heart closure (Fig. 2C,I), SHP-2 ${ }^{\mathrm{N} 308 \mathrm{D}}$ hearts remained as an open cardiac trough stretched along the dorsal-ventral axis (Fig. 2D,J). We further observed at these stages that SHP-2 ${ }^{\mathrm{N} 308 \mathrm{D}}$ hearts had significantly fewer cardiomyocytes (Tmy-positive cells; Fig. 2C,D) and proportionally less growth in their posterior aspects relative to controls, possibly representing a differential effect of SHP-2 ${ }^{\text {N308D }}$ along the anterior-posterior axis of the heart (Fig. 2I,J).

By stage 37, control heart tubes begin to undergo cardiac looping, leading to a shortening of the heart along the anteriorposterior axis and an elongation of the heart along the dorsalventral axis (Fig. 2E,K). By contrast, SHP-2 ${ }^{\mathrm{N} 308 \mathrm{D}}$ hearts exhibited a developmental delay, eventually closing dorsally to form a bilaminar heart tube that never underwent proper looping or chamber formation (Fig. 2F,L). Despite the failure of the heart to properly fuse, the SHP-2 ${ }^{\mathrm{N} 308 \mathrm{D}}$ cardiomyocytes began cellular movements associated with looping, including a leftward spiral of the cardiac tissue as noted by the relative shift of the inflow tract relative to the outflow tract (Fig. 2I-L). However, the SHP-2 ${ }^{\text {N308D }}$ cardiomyocytes formed a heart that was more compressed along the anterior-posterior axis versus controls but fully extended along the dorsal-ventral axis (compare Fig. 2K with 2L). Collectively, these studies demonstrate that introduction of the Noonanassociated mutation SHP-2 ${ }^{\mathrm{N} 308 \mathrm{D}}$ leads to a delay in cardiac morphogenetic movements between stages 29 and 33 and a resultant morphologically smaller and abnormal heart by stage 37 .

\section{The Noonan-associated mutation SHP-2 ${ }^{\mathrm{N308D}}$ leads to a delay or arrest of cardiomyocytes in M-phase} Cell counting of Tmy-positive cells in SHP-2 ${ }^{\mathrm{N} 308 \mathrm{D}}$ hearts relative to uninjected controls confirmed that there were fewer cardiomyocytes in SHP-2 ${ }^{\mathrm{N} 308 \mathrm{D}}$ hearts (Fig. 3A-E, $P \leq 0.05$ ). To determine whether the decrease in cardiomyocyte cell number was due to cell proliferation or programmed cell death, serial sections through the cardiac regions were triple immunostained with antiTmy to mark cardiomyocytes, DAPI to mark cell nuclei and either anti-phosphohistone $\mathrm{H} 3(\mathrm{pH} 3$ ) to mark cells in M phase (Fig. 3AD) or anti-cleaved caspase-3 to mark cells undergoing apoptosis (supplementary material Fig. S2). In each study, total cardiomyocytes from all sections taken from hearts at each stage were scored for the total number of triple-positive (Tmy, DAPI and either $\mathrm{pH} 3$ or cleaved caspase-3) versus double-positive cells (Tmy, DAPI). Interestingly, results from these studies demonstrate a dramatic increase in the cardiac mitotic index in SHP-2 ${ }^{\mathrm{N} 308 \mathrm{D}}$ embryos compared with SHP-2 ${ }^{\mathrm{FL}}$ embryos at stage 33 (Fig. 3F). This increase was tissue- and stage-specific with no significant increase in the cardiomyocyte mitotic index observed at either earlier or later stages (stage 29 and stage 37; Fig. 3F). As SHP-2 has been reported to have a role in cell survival (Yang et al., 2006b), the alteration in cardiomyocyte cell number might also be associated with an increase programmed cell death; however, at no time point analyzed could we detect any significant difference in programmed cell death (caspase-3 expression) between SHP$2^{\mathrm{N} 308 \mathrm{D}}$ and uninjected embryos (supplementary material Fig. S2). Because we observed an increase in the ratio of tropomyosinpositive cells in M-phase, as judged by the percentage of cells positive for $\mathrm{pH} 3$, and a concomitant decrease in the number of tropomyosin-positive cells, we interpret this observation to imply that cardiomyocytes in SHP-2 ${ }^{\mathrm{N} 308 \mathrm{D}}$ hearts are delayed or arrested in M-phase at stage 33.

\section{Increased SHP-2 activity leads to a failure of cardiac progenitors to incorporate into the developing heart}

A closer inspection of the cardiac region of SHP-2 ${ }^{\mathrm{N} 308 \mathrm{D}}$-derived embryos led to the identification of a population of cells in the lateral distal regions of the developing heart that, based on histological analysis, appeared to be unincorporated cardiac precursors cells (Fig. 4A-D). To determine the identity of these cells we generated an antibody against Xenopus TBX5, a protein that marks both undifferentiated and differentiated cardiomyocytes, and confirmed that the cells in the lateral regions of the pericardial cavity are TBX5 positive and MHC negative and are, therefore, 

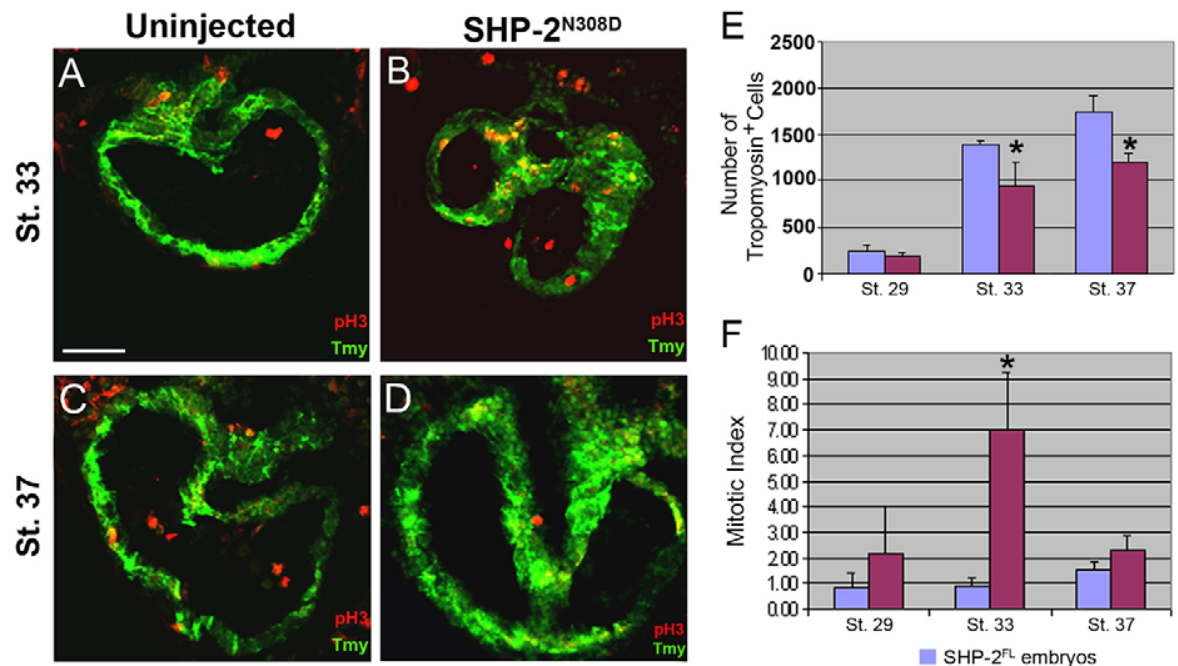

F

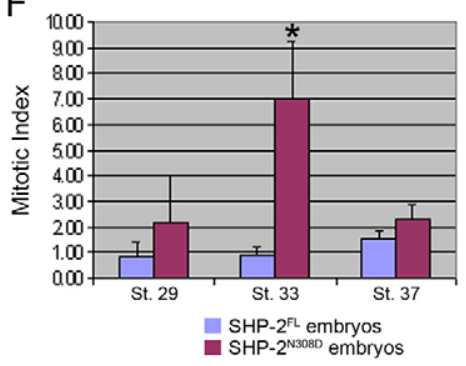

Fig. 3. SHP-2 ${ }^{\mathrm{N} 308 \mathrm{D}}$ leads to a delay of the cardiac cell cycle. (A-D) Transverse heart sections through stage $33(A, B)$ and stage 37 (C,D) Xenopus embryos stained with Tmy (green) and anti-phospho histone $\mathrm{H} 3$ (red), from uninjected $(A, C)$ and SHP-2 ${ }^{\mathrm{N} 308 \mathrm{D}}$-derived $(B, D)$ embryos (2 ng). Scale bar: $50 \mu \mathrm{m}$. $(\mathbf{E}, \mathbf{F})$ Graphs representing total number of Tmy-positive cells (E) and the mitotic index (F) in SHP-2 ${ }^{\mathrm{FL}}$ - (blue bars) and SHP-2 ${ }^{\mathrm{N} 308 \mathrm{D}}$ - (red bars) derived embryos at stages 29, 33 and 37. Bars represent the average of at least three embryos. Error bars represent s.d. ${ }^{*} P \leq 0.05$ (comparison of SHP-2 ${ }^{\mathrm{FL}}$ and SHP$2^{\mathrm{N} 308 \mathrm{D}}$ embryos) unincorporated cardiomyocyte progenitors (Fig. 4E-J). Collectively, these results demonstrate that SHP-2 ${ }^{\text {N308D }}$ leads to an incomplete integration of cardiomyocyte precursors and a concomitant delay or arrest in the cardiomyocyte cell cycle.

\section{SHP-2 acts to remodel the cardiac actin cytoskeleton via increased ROCK activity}

To investigate the molecular pathways that lead to cardiac abnormalities associated with SHP-2 ${ }^{\mathrm{N} 308 \mathrm{D}}$, we performed immunohistochemistry and detailed TEM analysis of cardiac tissue. We observed a dramatic increase in cardiac actin and fibrillin staining in SHP-2 ${ }^{\mathrm{N} 308 \mathrm{D}}$-derived embryos versus controls at stages when heart morphology is most severely disrupted (Fig. 5AI). Furthermore, ultrastructural analysis of SHP-2 ${ }^{\mathrm{N} 308 \mathrm{D}}$-derived hearts showed that SHP-2 ${ }^{\mathrm{N} 308 \mathrm{D}}$ cardiac tissue displayed an enrichment of extracellular matrix versus controls and that the heart tissue developed fewer sarcomeres. In addition, the sarcomeres that formed were arranged solely in concentric arrays compared with the organized cardiac myofibrils located throughout the myocardium of uninjected control-derived tissue (Fig. 5J-M). Collectively, these studies imply that the increase in SHP-2 phosphatase activity associated with SHP-2 ${ }^{\mathrm{N} 308 \mathrm{D}}$ leads to a disruption of myofibril formation and polarity in the developing heart.

To gain further insight into the cellular defects associated with the Noonan-associated mutation SHP-2 ${ }^{\mathrm{N} 308 \mathrm{D}}$ that might be affecting myofibrillar formation, we examined the ability of SHP-2 ${ }^{\mathrm{N} 308 \mathrm{D}}$ to regulate actin dynamics during the attachment and spreading of mesenchymal cells. Interestingly, SHP-2 ${ }^{\mathrm{N} 308 \mathrm{D}}$ expressing cells exhibited a marked reduction in cell spreading on fibronectin (FN)-coated coverglass in comparison with control or SHP-2 ${ }^{\mathrm{FL}}$-expressing cells, whereas those expressing the catalytically inactive SHP-2 ${ }^{\mathrm{N} 308 \mathrm{D}-\mathrm{PTP}}$ variant exhibited enhanced spreading on FN (Fig. 6A-J). Interestingly, all SHP-2 ${ }^{\mathrm{N} 308 \mathrm{D}}$ expressing cells plated for 40-180 minutes on FN displayed a marked increase in formation of a filamentous actin (F-actin) arc, which was not observed in either SHP-2 ${ }^{\mathrm{FL}}$ or the catalytically inactive SHP-2 ${ }^{\text {N308D-PTP }}$ variant (Fig. 6A,D,G). Actin arcs are bundles of actin filaments that are formed following the retraction of a lamellipodial projection. These contractile structures limit the rate of leading edge lamellipodial protrusions, but also limit their extent of retraction (i.e. they provide a block in rearward slipping).
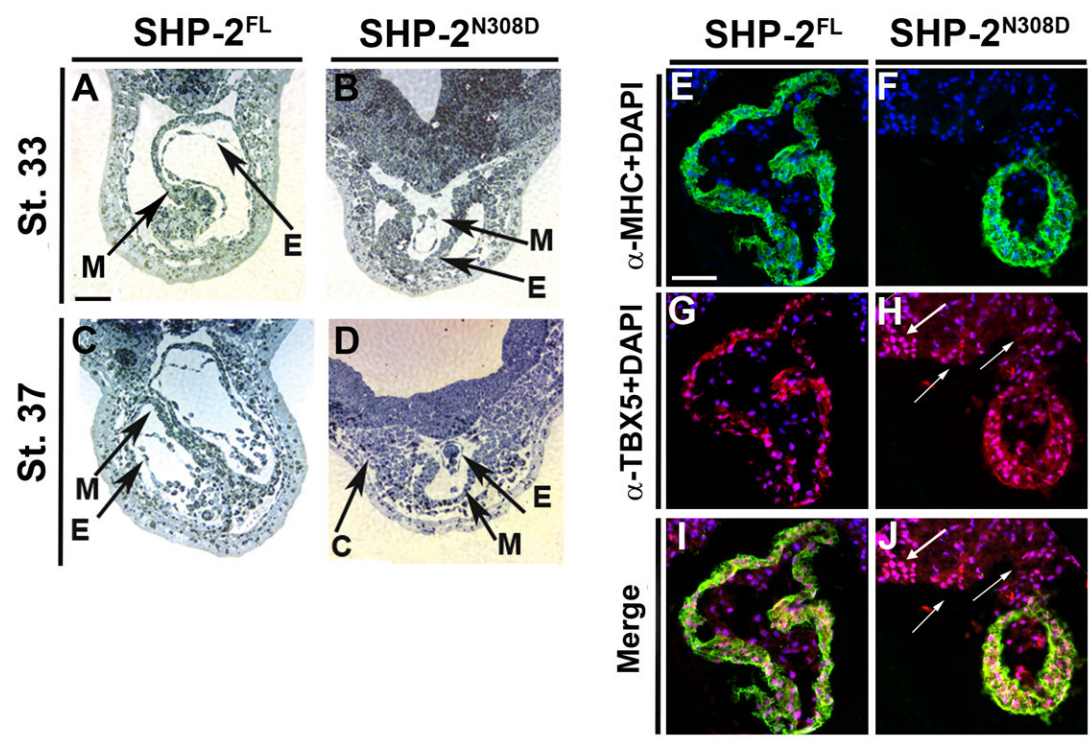

Fig. 4. A subpopulation of cardiac cells does not differentiate or incorporate into hearts of SHP-2 ${ }^{\text {N308D }}$ Xenopus embryos. (A-D) Transverse Toluidine Blue-stained histological sections of cardiac regions from stage $33(A, B)$ and stage $37(C, D)$ SHP-2 ${ }^{\mathrm{FL}}(\mathrm{A}, \mathrm{C})$ and SHP-2 ${ }^{\mathrm{N} 308 \mathrm{D}}(\mathrm{B}, \mathrm{D})$ embryos (2 ng). C, unincorporated cardiac cells; $E$, endocardium; $M$, myocardium. Scale bar: $50 \mu \mathrm{m}$. (E-J) Transverse sections through stage 37 hearts of SHP- $2^{\mathrm{FL}}(\mathrm{E}, \mathrm{G}, \mathrm{I})$ and SHP-2 ${ }^{\mathrm{N} 308 \mathrm{D}}(\mathrm{F}, \mathrm{H}, \mathrm{J})$ embryos (2 ng) stained with anti-MHC (green), anti-TBX5 (red) and DAPI (blue). Arrows mark TBX5 positive cells that have not incorporated into the heart. Scale bar: $50 \mu \mathrm{m}$. 

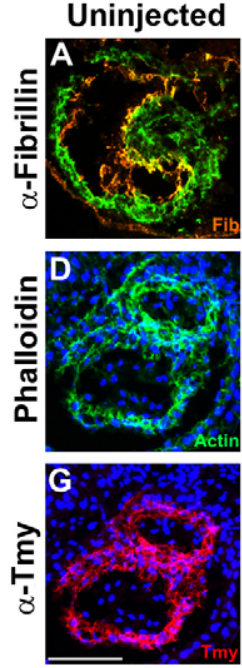

SHP-2 ${ }^{\mathrm{FL}}$
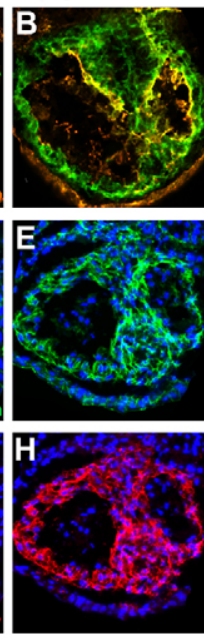

SHP-2 $2^{\mathrm{N} 308 \mathrm{D}}$
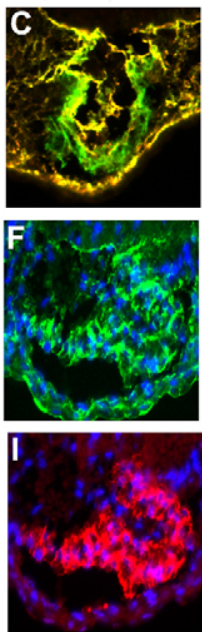
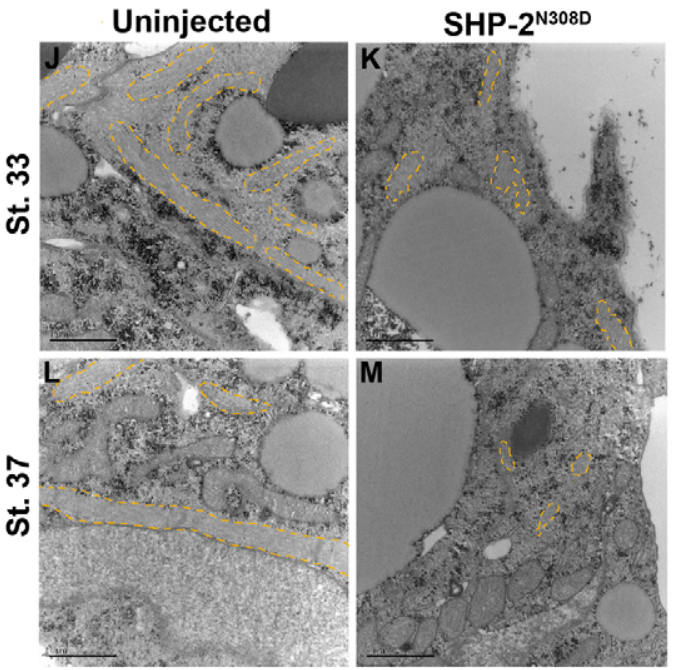

Fig. 5. SHP-2 ${ }^{\mathrm{N} 308 \mathrm{D}}$ leads to alterations in cardiac myofibril formation. (A-I) Transverse sections of stage 37 hearts from uninjected (A,D, $\left.\mathrm{G}\right)$, SHP-2 ${ }^{\mathrm{FL}}(\mathrm{B}, \mathrm{E}, \mathrm{H})$ or SHP-2 ${ }^{\mathrm{N} 308 \mathrm{D}}(\mathrm{C}, \mathrm{F}, \mathrm{I})$ Xenopus embryos (2 ng) immunostained for fibrillin (orange) and Tmy (green) (A-C), cardiac actin as detected by conjugated phalloidin (green; D-F) and tropomyosin (red) and DAPI (blue) (G-I). Scale bar: $100 \mu \mathrm{m}$. (J-M) Representative transmission electron micrographs of transverse images from stage $33(\mathrm{~J}, \mathrm{~K})$ or stage $37(\mathrm{~L}, \mathrm{M})$ heart tissue derived from uninjected $(\mathrm{J}, \mathrm{L})$ or SHP-2 ${ }^{\mathrm{N} 308 \mathrm{D}}(\mathrm{L}, \mathrm{M})$ embryos. Cardiac muscle fibrils are highlighted. Scale bars: $1 \mu \mathrm{m}$.

Thus, an inverse coupling between the formation and break-down of lamellipodia and actin arcs is necessary for step-wise forward movement during cell motility (Burnette et al., 2011). Consistent with the antagonistic nature of these actin-based structures on cell protrusions, we observed a lack of lamellipodia and associated nascent focal adhesions (as assessed by Y31-paxillin phosphorylation) in the SHP-2 ${ }^{\mathrm{N} 308 \mathrm{D}}$-expressing cells relative to either non-transfected controls (data not shown) or cells expressing SHP-2 ${ }^{\mathrm{FL}}$ or catalytically inactive SHP-2 ${ }^{\mathrm{N} 308 \mathrm{D}-\mathrm{PTP}}$ (Fig. 6B,E,H).

Although the precise mechanisms for control of the protrusion/retraction cycle are unknown, it is clear that dynamic regulation of Rac and Rho effectors is necessary for efficient cell motility. The Rho effector ROCK is known to be a major regulator of actin-based contractility, as it phosphorylates and activates myosin light chain. Recent studies by Lee et al. revealed that ROCK activity is suppressed in leading edge lamellipodia by Src-dependent phosphorylation of Y722 ROCK and that SHP-2 induced cell contraction by dephosphorylating Y722 (and thus de-repressing ROCK activity) (Lee and Chang, 2008). Consistent with SHP-2 ${ }^{\mathrm{N} 308 \mathrm{D}}$ functioning through a ROCK-dependent pathway, we found that inclusion of the pharmacological ROCK inhibitor Y27632 after the onset of cell spreading (40 minutes following plating on FN) fully attenuated SHP-2 ${ }^{\mathrm{N} 308 \mathrm{D}}$-dependent actin arcs and restored nascent focal adhesion complex formation (Fig. 6K-R).

To determine whether the SHP-2 ${ }^{\mathrm{N} 308 \mathrm{D}}$-ROCK pathway functions in cardiac tissue in vivo, we examined whether ROCK hyperactivity and downstream cytoskeletal reorganization within developing cardiomyocytes was responsible for the SHP-2 ${ }^{\mathrm{N} 308 \mathrm{D}}$ induced cardiac defects. SHP-2 ${ }^{\mathrm{N} 308 \mathrm{D}}$ embryos were incubated with Y27632 as used above, during crucial stages of cardiac development, post-cardiac field fusion at the ventral midline. We observed a dramatic reduction in pericardial edema, an indicator of cardiac malfunction, in rescued SHP- $2^{\mathrm{N} 308 \mathrm{D}}$-injected embryos compared with non-rescued sibling controls (Fig. 7C,D). Furthermore, heart morphology and cardiac looping in rescued SHP-2 ${ }^{\mathrm{N} 308 \mathrm{D}}$-injected embryos was found to be indistinguishable from uninjected sibling embryos $(81.5 \%$ embryos rescued from three independent experiments with a total of 27 embryos) when compared with non-rescued SHP-2 ${ }^{\mathrm{N} 308 \mathrm{D}}$ siblings $(28.6 \%$ normal heart morphology from three independent experiments with a total of 28 embryos, $P=0.0001$ ) (Fig. 7E-I). Taken together, these studies demonstrate that SHP-2 ${ }^{\mathrm{N} 308 \mathrm{D}}$ expression inhibits cell spreading and motility in cells and alters actin-dependent adhesion/migration processes in the developing heart by inducing elevated or sustained ROCK activation and aberrant myosin-dependent cytoskeletal rearrangements.

\section{DISCUSSION \\ Increase in SHP-2 activity disrupts actin myofibril development}

Our studies imply that a primary function of SHP-2 in the heart is to regulate actin dynamics. The morphological and cellular modeling analyses, together with the TEM data, all indicate alterations in actin organization at stage 33 , a time point when we can detect no other patterning abnormalities in the developing heart or embryo. Furthermore, we demonstrated that in mesenchymal cells SHP-2 alters cell spreading and adhesion dynamics via actin accumulation, and that this directly translated to our Xenopus in vivo model whereby depletion of ROCK activity rescued SHP-2 ${ }^{\mathrm{N} 308 \mathrm{D}}$-induced cardiac defects.

In general, many of the $\mathrm{SH} 2$ domain disease-causing mutations tested to date result in enhanced catalytic activity (likely to be due to relief of SH2-mediated auto-inhibition), whereas mutations associated with LEOPARD syndrome (in which the mutations are typically localized within the catalytic cleft) result in lower catalytic activity than wild-type constructs (Digilio et al., 2002; Legius et al., 2002). No studies to date have examined the affect of Noonan syndrome-causing SHP-2 variants on site-specific ROCK dephosphorylation; however, it was shown that expression of a SHP-2 gain-of-function mutation associated with acute AML (SHP-2 ${ }^{\mathrm{E} 76 \mathrm{G}}$ ) (Bentires-Alj et al., 2004) produced an adhesion defect in D2 cells and that the adhesion defect was sensitive to ROCK inhibition (Lee et al., 2008), substantiating our findings that reduced cell adhesion and spreading by SHP-2 ${ }^{\mathrm{N} 308 \mathrm{D}}$ is likely to be 

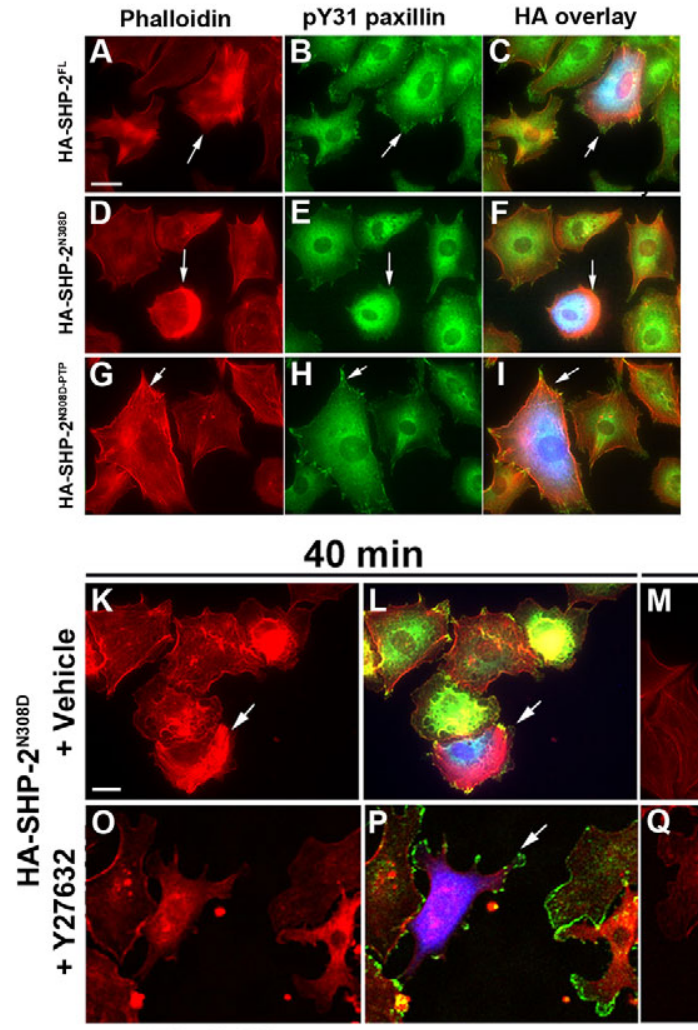

Phalloidin
$40 \mathrm{~min}$

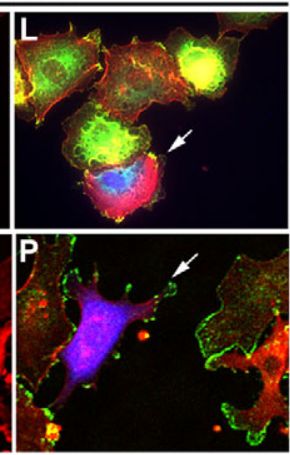

$\mathrm{HA}+\mathrm{pY} 31$ paxillin merge

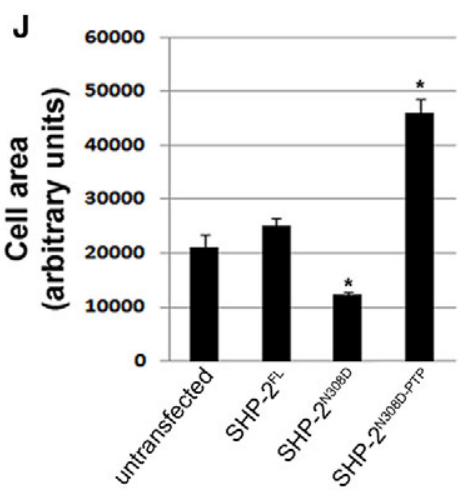

$180 \min$

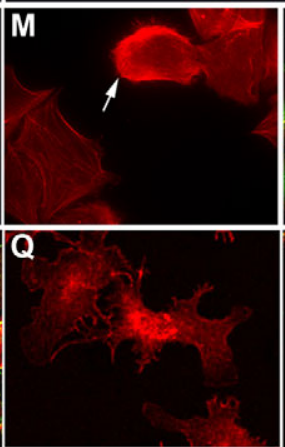

Phalloidin

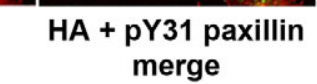

Fig. 6. SHP-2 ${ }^{\mathrm{N} 308 \mathrm{D}}$ regulates actin deposition. (A-I) Cells were transfected with HA-SHP-2 $2^{\mathrm{FL}}(\mathrm{A}-\mathrm{C}), \mathrm{HA}-\mathrm{SHP}-2^{\mathrm{N} 308 \mathrm{D}}$ (D-F) or HA-SHP-2 ${ }^{\mathrm{N} 308 \mathrm{D}-\mathrm{PTP}}(\mathrm{G}-\mathrm{I})$, plated on FN and stained for phalloidin (red) $(A, D, G)$, pY31 paxillin (green) $(B, E, H)$, and $H A$ (blue) to identify transfected cells $(C, F, I)$. Arrows denote lamellipodia and focal adhesion complexes. (J) 2D cell area as a measure of cell spreading was calculated from 150-200 cells transfected with the designated construct, using ImageJ software tools. Error bars represent s.e.m. ${ }^{*} P \leq 0.05$.

(K-R) Inhibition of ROCK activity rescues SHP-2 ${ }^{\text {N308D }}$ cell rounding phenotype. SHP$2^{\mathrm{N} 308 \mathrm{D}}$-transfected cells (blue; L,N,P,R) treated with $\mathrm{Y} 27632(\mathrm{O}-\mathrm{R})$ for either 40 $(\mathrm{O}, \mathrm{P})$ or180 $(\mathrm{Q}, \mathrm{R})$ minutes displayed reduced actin arc formation and re-established focal adhesion complexes (arrows) compared with vehicle-treated cells (K-N). Scale bars: $10 \mu \mathrm{m}$.
ROCK-activity dependent. Interestingly, these studies provided evidence that phosphorylated Y722 ROCKII can interact directly with the catalytic site in SHP-2, and that a SHP-2 construct lacking the amino-terminus had a greater propensity to dephosphorylate ROCKII than full length SHP-2. Thus, these data collectively corroborate an auto-inhibitory mechanism on the phosphatase domain and the specificity of this substrate for SHP-2.

One outcome of overexpressing SHP-2 ${ }^{\mathrm{N} 308 \mathrm{D}}$ was a cardiacspecific increase in fibrillin deposition as well as a visible remodeling of the actin cytoskeleton in cardiomyocytes. It was reported that ROCK knockout (-/-) and heterogenous (+/-) mice display reduced fibrosis after cardiac injury (Rikitake et al., 2005; Haudek et al., 2009); therefore, we can speculate that in our model, SHP-2 ${ }^{\mathrm{N} 308 \mathrm{D}}$-induced hyperactivation of ROCK in developing cardiomyocytes results in an augmented fibrosis-like phenotype. It is also worth considering that ROCK substrates that function in actin remodeling, such as LIM kinase (Lin et al., 2003; Shea et al., 2008), adducin (Fukata et al., 1999) and cofilin (Arber et al., 1998; Maekawa et al., 1999; Lin et al., 2003), might be altered in relation to SHP-2 ${ }^{\mathrm{N} 308 \mathrm{D}}$ activity and thereby modify actin dynamics, but this requires further investigation.

Our investigations have shown that the increased phosphatase activity of SHP-2 ${ }^{\mathrm{N} 308 \mathrm{D}}$ leads to a perturbation of cardiac cells incorporating into the heart and differentiating into cardiomyocytes. It is feasible to hypothesize that a combination of altered cardiomyocyte proliferation together with disturbances in cell adhesion/migration produced by ROCK-induced increases in actinmyosin crosslinking and fibrillin/ECM deposition, resulted in the failure or delay of cardiac precursor cells to migrate and fuse to form the developing heart tube. Alternatively, one may conclude that SHP-2 ${ }^{\mathrm{N} 308 \mathrm{D}}$-induced ROCK hyperactivity might inadvertently stall or delay cardiac differentiation and the incorporation of cardiac precursors into striated cardiac muscle. Previous work on early chick and mouse development determined that a reduction in ROCK activity resulted in the precocious and expanded expression of the cardiac differentiation markers cardiac $\alpha$-actin, GATA4 and SRF (Wei et al., 2001). SHP-2 ${ }^{\mathrm{N} 308 \mathrm{D}}$-altered myofibril organization and diminished sarcomere formation might, therefore, result from a block in striated muscle $\alpha$-actin expression and subsequent cardiac muscle differentiation. It is also possible that SHP-2 ${ }^{\mathrm{N} 308 \mathrm{D}}$ activation of ROCK translates to impaired cardiac morphogenesis by physiological contributions, such as those demonstrated by Vahebi et al., where constitutively active ROCK is able to phosphorylate the cardiac troponin complex leading to reduced ATPase activity and calcium responses, thereby affecting muscle contraction and diminishing consequent growth and development (Hahn et al., 2000; Iwamoto et al., 2000; Schildmeyer et al., 2000; Vahebi et al., 2005).

Interestingly, Wei et al. (Wei et al., 2001) demonstrated how Y27632 introduction on early-stage chick embryos resulted in pronounced cardia bifida (via defects in cardiac mesoderm migration and/or fusion at the midline), whereas later administration had less prominent effects, suggesting that temporal control of ROCK activity is crucial for normal cardiac morphogenesis. Overstimulation of ROCK activity by SHP-2 ${ }^{\mathrm{N} 308 \mathrm{D}}$ might, therefore, have detrimental effects on cardiac development in both a spatial and temporal manner.

\section{Cardiac specificity of SHP-2 ${ }^{\text {N308D }}$}

What then leads to the tissue-specific effects of the SHP-2 ${ }^{\mathrm{N} 308 \mathrm{D}}$ mutation? One hypothesis is that the heart is particularly sensitive to changes in SHP-2 phosphatase activity and, thus, prolonged or 
Uninjected

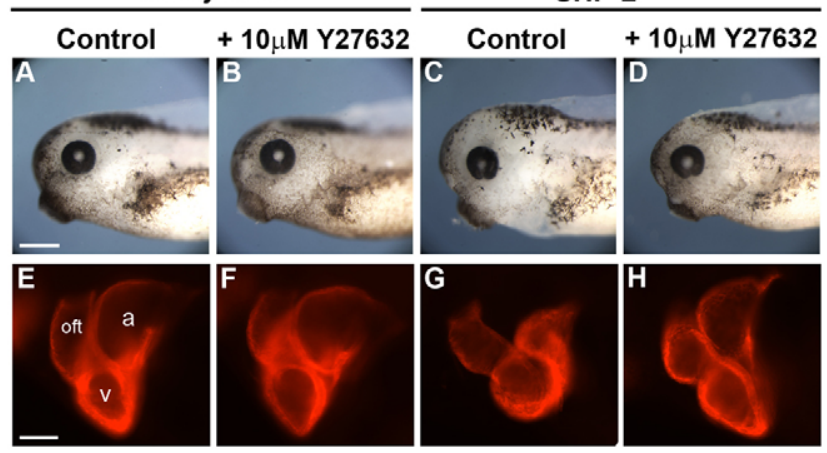

I

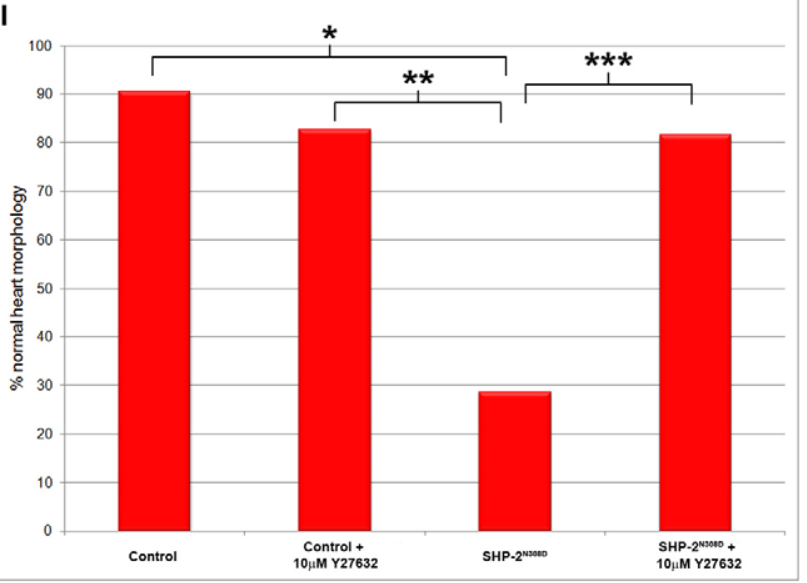

Fig. 7. ROCK inhibition rescues the cardiac morphogenetic defects seen in SHP-2 ${ }^{\text {N308D }}$ embryos. (A-D) Brightfield images of stage 40 Xenopus embryos from appropriate conditions. Note that pericardial edema in SHP-2 ${ }^{\mathrm{N} 308 \mathrm{D}}$ embryo $(3.6 \mathrm{ng} ; \mathrm{C})$ is absent in sibling incubated with Y27632 (D) and uninjected controls (A,B). Scale bar: 2 $\mathrm{mm}$. (E-H) Immunofluorescent images of cleared hearts stained with anti-MHC, indicating the rescue of cardiac malformation and looping defects in SHP-2 ${ }^{\text {N308D }}$ embryo $(G)$ compared with sibling incubated in Y27632 (H) and uninjected controls (E,F). Scale bar: $100 \mu \mathrm{m}$. (I) Graph of percentage of normal heart morphology at stage 40 in control and SHP-2 ${ }^{\mathrm{N} 308 \mathrm{D}}$ sibling embryos treated with $10 \mu \mathrm{M}$ ROCK inhibitor Y27632. Statistical significance is denoted as ${ }^{*} P \leq 0.0001, * * P=0.0002$, $* * * P=0.0001$ using Fisher's exact two-tailed test. Anterior is to the left, posterior to the right in all images. a, atrium; oft, outflow tract; $v$, ventricle.

elevated levels of SHP-2 linked with Noonan syndrome-associated mutations leads to cardiac defects. However, we found that neither decreasing nor increasing the amount of any of the SHP-2 variants $\left(\mathrm{SHP}-2^{\mathrm{FL}}, \mathrm{SHP}-2^{\mathrm{E} 76 \mathrm{~A}}\right.$ or $\mathrm{SHP}-2^{\mathrm{N} 308 \mathrm{D}}$ ) had an effect on tissue specificity in Xenopus. Consistent with these observations, the JMML- and AML-associated mutation SHP-2 ${ }^{\text {E76A }}$ has been demonstrated to have elevated phosphatase activity relative to that of SHP- $2^{\mathrm{FL}}$ and can hyperstimulate ROCK activity in a manner similar to that of SHP-2 ${ }^{\mathrm{N} 308 \mathrm{D}}$; yet this mutation, unlike SHP-2 ${ }^{\mathrm{N} 308 \mathrm{D}}$, has no effect on heart development (Fragale et al., 2004; Lee and Chang, 2008) (Fig. 1C-H). Taken together, these observations argue against a model in which varying SHP-2 phosphatase activity is the cause of the cardiac-specific defects observed in Noonan syndrome patients.

Instead, we favor a model in which SHP-2 ${ }^{\mathrm{N} 308 \mathrm{D}}$ and other Noonan syndrome-associated mutations have greater access to subcellular compartments, which, in the heart, are enriched with
SHP-2 substrates. In accordance with this model, it was observed that ROCK is more highly expressed in embryonic heart tissue during periods of hyperplasia and its expression is downregulated as cardiac development switches to a period of hypertrophic growth (Ahuja et al., 2007). In line with these findings, we observed in our studies a stage-specific effect for SHP-2 ${ }^{\mathrm{N} 308 \mathrm{D}}$ in Xenopus at a period of cardiac hyperplastic growth (Goetz et al., 2006; Fishman and Chien, 1997; Harvey, 2002; Kolker et al., 2000; Mohun et al., 2003; Mohun et al., 2000). Our model is supported further by the finding that subcellular compartments can be enriched with ROCK. For example, ROCK is localized to the cleavage furrow during cytokinesis and is therefore exposed to a specific subset of nuclear-localized effectors (Kosako et al., 2000; Yokoyama et al., 2005). Crucially, mouse embryos cultured with ROCK inhibitors displayed cardiac hypoplasia and reduced cardiomyocyte proliferation and, moreover, Rock $1^{-/}$ cardiomyocytes are protected from apoptosis in a pressure overload model. Therefore, ROCK activity, although involved in global cellular processes such as actin-myosin signaling and cytokinesis, has tissue-specific requirements during development (Chang et al., 2006; reviewed by Loirand et al., 2006; Zhao and Rivkees, 2003). Thus, we propose that during periods of increased cardiomyocyte proliferation, there coincides an increased demand for ROCK, which is at least partially met by a relative upregulation of ROCK, potentially in subcellular compartments to which Noonan syndrome-associated mutations have greater access.

Together, these investigations highlight the multitude of processes in which ROCK functions during heart development, and further imply that signaling downstream of the SHP2/ROCK module is complex and ultimately system-, stage- and context-dependent. Our studies in Xenopus reveal novel mechanisms, and potentially new downstream effectors including ROCK, by which Noonan-associated mutations in SHP-2 can cause cardiac malformation. To this end, the ROCK inhibitor fausidil has successfully been shown to reduce fibrosis and improve cardiac function in animal models of heart failure (Wang et al., 2011) as well as in clinical trials studying ROCK signaling in pulmonary hypertension (Doggrell et al., 2005). Therefore, we hope these studies will provide further insight, as well as new targets, in the development of Noonan-syndrome therapeutic interventions.

\section{Acknowledgements}

We thank Victoria Madden and Elena Davis of the UNC Microscopy Services Laboratory for assistance with TEM. We also thank Chris Showell and Larysa Pevny for critical reading of the manuscript. The tropomyosin antibody developed by J.C. Lin was obtained from the Developmental Studies Hybridoma Bank developed under the auspices of the National Institute of Child Health and Development (NICHD) and maintained by the University of lowa.

\section{Funding}

This work was supported by grants from the National Institutes of Health $(\mathrm{NIH})$ [DE018825 and RO1 HL089641 to F.L.C.] and the American Heart Association (AHA) [Established Investigator Award to F.L.C.]. Y.L. was funded by an NIH minority supplement [NHLBI HL075256-01S1]. Deposited in PMC for release after 12 months.

\section{Competing interests statement}

The authors declare no competing financial interests.

\section{Supplementary material}

Supplementary material available online at

http://dev.biologists.org/lookup/suppl/doi:10.1242/dev.067579/-/DC1 
References

Ahuja, P., Perriard, E., Pedrazzini, T., Satoh, S., Perriard, J. C. and Ehler, E. (2007). Re-expression of proteins involved in cytokinesis during cardiac hypertrophy. Exp. Cell Res. 313, 1270-1283.

Arber, S., Barbayannis, F. A., Hanser, H., Schneider, C., Stanyon, C. A., Bernard, O. and Caroni, P. (1998). Regulation of actin dynamics through phosphorylation of cofilin by LIM-kinase. Nature 393, 805-809.

Bennett, A. M., Hausdorff, S. F., O’Reilly, A. M., Freeman, R. M. and Neel, B. G. (1996). Multiple requirements for SHPTP2 in epidermal growth factormediated cell cycle progression. Mol. Cell. Biol. 16, 1189-1202.

Bentires-Alj, M., Paez, J. G., David, F. S., Keilhack, H., Halmos, B., Naoki, K. Maris, J. M., Richardson, A., Bardelli, A., Sugarbaker, D. J. et al. (2004). Activating mutations of the noonan syndrome-associated SHP2/PTPN11 gene in human solid tumors and adult acute myelogenous leukemia. Cancer Res. 64, 8816-8820.

Brown, D. D., Christine, K. S., Showell, C. and Conlon, F. L. (2007). Small heat shock protein Hsp27 is required for proper heart tube formation. Genesis $\mathbf{4 5}$ 667-678.

Burnette, D. T., Manley, S., Sengupta, P., Sougrat, R., Davidson, M. W., Kachar, B. and Lippincott-Schwartz, J. (2011). A role for actin arcs in the leading-edge advance of migrating cells. Nat. Cell Biol. 13, 371-381.

Chang, J., Xie, M., Shah, V. R., Schneider, M. D., Entman, M. L., Wei, L. and Schwartz, R. J. (2006). Activation of Rho-associated coiled-coil protein kinase 1 (ROCK-1) by caspase-3 cleavage plays an essential role in cardiac myocyte apoptosis. Proc. Natl. Acad. Sci. USA 103, 14495-14500.

Digilio, M. C., Conti, E., Sarkozy, A., Mingarelli, R., Dottorini, T., Marino, B., Pizzuti, A. and Dallapiccola, B. (2002). Grouping of multiplelentigines/LEOPARD and Noonan syndromes on the PTPN11 gene. Am. J. Hum. Genet. 71, 389-394.

Doggrell, S. A. (2005). Rho-kinase inhibitors show promise in pulmonary hypertension. Expert Opin. Investig. Drugs 14, 1157-1159.

Feng, G. S. (1999). Shp-2 tyrosine phosphatase: signaling one cell or many. Exp. Cell Res. 253 , 47-54.

Fishman, M. C. and Chien, K. R. (1997). Fashioning the vertebrate heart: earliest embryonic decisions. Development 124, 2099-2117

Fragale, A., Tartaglia, M., Wu, J. and Gelb, B. D. (2004). Noonan syndromeassociated SHP2/PTPN11 mutants cause EGF-dependent prolonged GAB1 binding and sustained ERK2/MAPK1 activation. Hum. Mutat. 23, 267-277.

Fukata, Y., Oshiro, N., Kinoshita, N., Kawano, Y., Matsuoka, Y., Bennett, V. Matsuura, Y. and Kaibuchi, K. (1999). Phosphorylation of adducin by Rhokinase plays a crucial role in cell motility. J. Cell Biol. 145, 347-361.

Georgescu, M. M., Kirsch, K. H., Kaloudis, P., Yang, H., Pavletich, N. P. and Hanafusa, H. (2000). Stabilization and productive positioning roles of the C2 domain of PTEN tumor suppressor. Cancer Res. 60, 7033-7038.

Goetz, S. C., Brown, D. D. and Conlon, F. L. (2006). TBX5 is required for embryonic cardiac cell cycle progression. Development 133, 2575-2584.

Hahn, A., Heusinger-Ribeiro, J., Lanz, T., Zenkel, S. and Goppelt-Struebe, M. (2000). Induction of connective tissue growth factor by activation of heptahelica receptors. Modulation by Rho proteins and the actin cytoskeleton. J. Biol. Chem. 275, 37429-37435

Harvey, R. P. (2002). Patterning the vertebrate heart. Nat. Rev. Genet. 3, 544556.

Haudek, S. B., Gupta, D., Dewald, O., Schwartz, R. J., Wei, L., Trial, J. and Entman, M. L. (2009). Rho kinase-1 mediates cardiac fibrosis by regulating fibroblast precursor cell differentiation. Cardiovasc. Res. 83, 511-518.

Iwamoto, H. (2000). Influence of ionic strength on the actomyosin reaction steps in contracting skeletal muscle fibers. Biophys. J. 78, 3138-3149.

Kolker, S., Tajchman, U. and Weeks, D. L. (2000). Confocal Imaging of early heat development in Xenopus laevis. Dev. Biol. 218, 64-73

Kosaki, K., Suzuki, T., Muroya, K., Hasegawa, T., Sato, S., Matsuo, N., Kosaki, R., Nagai, T., Hasegawa, Y. and Ogata, T. (2002). PTPN11 (proteintyrosine phosphatase, nonreceptor-type 11) mutations in seven Japanese patients with Noonan syndrome. J. Clin. Endocrinol. Metab. 87, 3529-3533.

Kosako, H., Yoshida, T., Matsumura, F., Ishizaki, T., Narumiya, S. and Inagaki, M. (2000). Rho-kinase/ROCK is involved in cytokinesis through the phosphorylation of myosin light chain and not ezrin/radixin/moesin proteins at the cleavage furrow. Oncogene 19,6059-6064.

Kratz, C. P., Niemeyer, C. M., Castleberry, R. P., Cetin, M., Bergstrasser, E., Emanuel, P. D., Hasle, H., Kardos, G., Klein, C., Kojima, S. et al. (2005). The mutational spectrum of PTPN11 in juvenile myelomonocytic leukemia and Noonan syndrome/myeloproliferative disease. Blood 106, 2183-2185

Langdon, Y. G., Goetz, S. C., Berg, A. E., Swanik, J. T. and Conlon, F. L. (2007). SHP-2 is required for the maintenance of cardiac progenitors. Development 134, 4119-4130.

Lee, H. H. and Chang, Z. F. (2008). Regulation of RhoA-dependent ROCKI activation by Shp2. J. Cell Biol. 181, 999-1012.

Legius, E., Schrander-Stumpel, C., Schollen, E., Pulles-Heintzberger, C., Gewillig, M. and Fryns, J. P. (2002). PTPN11 mutations in LEOPARD syndrome. J. Med. Genet. 39, 571-574.
Lin, T., Zeng, L., Liu, Y., DeFea, K., Schwartz, M. A., Chien, S. and Shyy, J. Y. (2003). Rho-ROCK-LIMK-cofilin pathway regulates shear stress activation of sterol regulatory element binding proteins. Circ. Res. 92, 1296-1304

Loh, M. L., Reynolds, M. G., Vattikuti, S., Gerbing, R. B., Alonzo, T. A., Carlson, E., Cheng, J. W., Lee, C. M., Lange, B. J. and Meshinchi, S. (2004). PTPN11 mutations in pediatric patients with acute myeloid leukemia: results from the Children's Cancer Group. Leukemia 18, 1831-1834.

Loirand, G., Guerin, P. and Pacaud, P. (2006). Rho kinases in cardiovascular physiology and pathophysiology. Circ. Res. 98, 322-334.

Maekawa, M., Ishizaki, T., Boku, S., Watanabe, N., Fujita, A., Iwamatsu, A. Obinata, T., Ohashi, K., Mizuno, K. and Narumiya, S. (1999). Signaling from Rho to the actin cytoskeleton through protein kinases ROCK and LIM-kinase. Science 285, 895-898.

Maheshwari, M., Belmont, J., Fernbach, S., Ho, T., Molinari, L., Yakub, I., Yu, F., Combes, A., Towbin, J., Craigen, W. J. et al. (2002). PTPN11 mutations in Noonan syndrome type I: detection of recurrent mutations in exons 3 and 13 . Hum. Mutat. 20, 298-304.

Mohun, T., Orford, R. and Shang, C. (2003). The origins of cardiac tissue in the amphibian, Xenopus laevis. Trends Cardiovasc. Med. 13, 244-248.

Mohun, T. J., Leong, L. M., Weninger, W. J. and Sparrow, D. B. (2000). The morphology of heart development in Xenopus laevis. Dev. Biol. 218, 74-88.

Musante, L., Kehl, H. G., Majewski, F., Meinecke, P., Schweiger, S., GillessenKaesbach, G., Wieczorek, D., Hinkel, G. K., Tinschert, S., Hoeltzenbein, M. et al. (2003). Spectrum of mutations in PTPN11 and genotype-phenotype correlation in 96 patients with Noonan syndrome and five patients with cardiofacio-cutaneous syndrome. Eur. J. Hum. Genet. 11, 201-206.

Nieuwkoop, P. D. and Faber, J. (1975). Normal Table of Xenopus laevis (Daudin). Amsterdam, The Netherlands: North Holland.

Noonan, J. A. (1968). Hypertelorism with Turner phenotype. A new syndrome with associated congenital heart disease. Am. J. Dis. Child 116, 373-380.

Noonan, J. A. (1994). Noonan syndrome. An update and review for the primary pediatrician. Clin. Pediatr. 33, 548-555

Pawson, T. (1994). Tyrosine kinase signalling pathways. Princess Takamatsu Symp. 24, 303-322

Qu, C. K. (2000). The SHP-2 tyrosine phosphatase: signaling mechanisms and biological functions. Cell Res. 10, 279-288.

Rikitake, Y., Oyama, N., Wang, C. Y., Noma, K., Satoh, M., Kim, H. H. and Liao, J. K. (2005). Decreased perivascular fibrosis but not cardiac hypertrophy in ROCK1+/- haploinsufficient mice. Circulation 112, 2959-2965.

Saxton, T. M. and Pawson, T. (1999). Morphogenetic movements at gastrulation require the SH2 tyrosine phosphatase Shp2. Proc. Natl. Acad. Sci. USA 96, 37903795

Saxton, T. M., Henkemeyer, M., Gasca, S., Shen, R., Rossi, D. J., Shalaby, F., Feng, G. S. and Pawson, T. (1997). Abnormal mesoderm patterning in mouse embryos mutant for the SH2 tyrosine phosphatase Shp-2. EMBO J. 16, 2352 2364

Schildmeyer, L. A., Braun, R., Taffet, G., Debiasi, M., Burns, A. E., Bradley, A. and Schwartz, R. J. (2000). Impaired vascular contractility and blood pressure homeostasis in the smooth muscle alpha-actin null mouse. FASEB J. 14, 22132220

Shea, K. F., Wells, C. M., Garner, A. P. and Jones, G. E. (2008). ROCK1 and LIMK2 interact in spread but not blebbing cancer cells. PLOS ONE 3, e3398.

Smith, J. C. and Slack, J. M. W. (1983). Dorsalization and neural induction: properties of the organizer in Xenopus laevis. J. Embryol. Exp. Morphol. 78, 299317.

Tang, T. L., Freeman, R. M., Jr, O’Reilly, A. M., Neel, B. G. and Sokol, S. Y. (1995). The SH2-containing protein-tyrosine phosphatase SH-PTP2 is required upstream of MAP kinase for early Xenopus development. Cell 80, 473-483.

Tartaglia, M., Mehler, E. L., Goldberg, R., Zampino, G., Brunner, H. G. Kremer, H., van der Burgt, I., Crosby, A. H., Ion, A., Jeffery, S. et al. (2001). Mutations in PTPN11, encoding the protein tyrosine phosphatase SHP-2, cause Noonan syndrome. Nat. Genet. 29, 465-468.

Tartaglia, M., Kalidas, K., Shaw, A., Song, X., Musat, D. L., van der Burgt, I., Brunner, H. G., Bertola, D. R., Crosby, A., Ion, A. et al. (2002). PTPN11 mutations in Noonan syndrome: molecular spectrum, genotype-phenotype correlation, and phenotypic heterogeneity. Am. J. Hum. Genet. 70, 1555-1563.

Tartaglia, M., Niemeyer, C. M., Fragale, A., Song, X., Buechner, J., Jung, A., Hahlen, K., Hasle, H., Licht, J. D. and Gelb, B. D. (2003). Somatic mutations in PTPN1 1 in juvenile myelomonocytic leukemia, myelodysplastic syndromes and acute myeloid leukemia. Nat. Genet. 34, 148-150.

Vahebi, S., Kobayashi, T., Warren, C. M., de Tombe, P. P. and Solaro, R. J. (2005). Functional effects of rho-kinase-dependent phosphorylation of specific sites on cardiac troponin. Circ. Res. 96, 740-747.

Van Vactor, D., O'Reilly, A. M. and Neel, B. G. (1998). Genetic analysis of protein tyrosine phosphatases. Curr. Opin. Genet. Dev. 8, 112-126.

Wang, N., Guan, P., Zhang, J. P., Chang, Y. Z., Gu, L. J., Hao, F. K., Shi, Z. H., Wang, F. Y. and Chu, L. (2011). Preventive effects of fasudil on adriamycininduced cardiomyopathy: possible involvement of inhibition of RhoA/ROCK pathway. Food Chem. Toxicol. 49, 2975-2982. 
Wei, L., Roberts, W., Wang, L., Yamada, M., Zhang, S., Zhao, Z., Rivkees, S. A., Schwartz, R. J. and Imanaka-Yoshida, K. (2001). Rho kinases play an obligatory role in vertebrate embryonic organogenesis. Development 128, 29532962

Wilson, P. A. and Hemmati-Brivanlou, A. (1995). Induction of epidermis and inhibition of neural fate by Bmp-4. Nature 376, 331-333.

Yang, W., Klaman, L. D., Chen, B., Araki, T., Harada, H., Thomas, S. M., George, E. L. and Neel, B. G. (2006a). An Shp2/SFK/Ras/Erk signaling pathway controls trophoblast stem cell survival. Dev. Cell 10, 317-327.

Yang, W., Klaman, L. D., Chen, B., Araki, T., Harada, H., Thomas, S. M., George, E. L. and Neel, B. G. (2006b). An Shp2/SFK/Ras/Erk signaling pathway controls trophoblast stem cell survival. Dev. Cell 10, 317-327.
Yokoyama, T., Goto, H., Izawa, I., Mizutani, H. and Inagaki, M. (2005). Aurora-B and Rho-kinase/ROCK, the two cleavage furrow kinases, independently regulate the progression of cytokinesis: possible existence of a novel cleavage furrow kinase phosphorylates ezrin/radixin/moesin (ERM). Genes Cells 10, 127-137.

Zhang, J., Somani, A. K. and Siminovitch, K. A. (2000). Roles of the SHP-1 tyrosine phosphatase in the negative regulation of cell signalling. Semin. Immunol. 12, 361-378.

Zhao, Z. and Rivkees, S. A. (2003). Rho-associated kinases play an essential role in cardiac morphogenesis and cardiomyocyte proliferation. Dev. Dyn. 226, 24-32. 